\title{
A GIS based empirical model to simulate air temperature variations in the Göteborg urban area during the night
}

\author{
M. K. Svensson*, I. Eliasson, B. Holmer \\ Laboratory of Climatology, Department of Physical Geography, Earth Sciences Centre, Göteborg University, Box 460, \\ 40530 Göteborg, Sweden
}

\begin{abstract}
This paper presents a GIS based empirical model to simulate wind and/or air temperature variations over land. The technique is based on meteorological data (wind direction and wind speed, temperature and cloud cover) from one permanent reference station, a digital local climate map and a digital land use map. The focus of the paper is to apply and evaluate the technique for clear and calm night-time weather conditions in Göteborg, Sweden. Hourly data from a monitoring network including 31 temperature stations are used in the verification of simulations made using the model. These data are also used for a description of geographical factors that influence air temperature variations in the Göteborg urban district. The technique is a potential tool for urban planning purposes but the verification shows that further improvements are needed. The main problems identified are related to details in the climate map but also to some of the algorithms that need to be refined.
\end{abstract}

KEY WORDS: Empirical modelling · Algorithms · Local climate $\cdot$ Land use/land cover · Göteborg · Urban heat island · GIS · Urban planning

Resale or republication not permitted without written consent of the publisher

\section{INTRODUCTION}

Several attempts have been made to integrate climate and planning, and develop models and methods to study or simulate the impact of climate on human comfort, air pollution, energy consumption and other factors. In a comprehensive review of methodologies and techniques available to foretell the climatic impact of alternative design strategies, Oke (1984) defines 3 main groups: numerical models, physical models and empirically based methods.

Numerical models are constantly being developed and refined for simulating atmospheric processes on different scales and the range of models is extremely broad. The use of numerical modelling in applied meteorology and climatology is often focused on simulating the wind field and associated effects such as the spread of pollutants, but simulations of the thermal cli-

*E-mail: maries@gvc.gu.se mate and its effect on, for example, energy consumption and human comfort have also been made; see reviews by Pielke \& Pearce (1994), Arnfield (1998b, $2000)$ and Sturman $(1998,2000)$. There is no doubt that numerical models could become a powerful tool for urban planning. A bioclimate model developed by Jendritzky et al. (1999) and Friedrich et al. (2001) has, for example, successfully been applied in urban planning in Germany. In general, however, despite the developments during the latest decades, the problems identified by Oke (1984) concerning validation, input demands and outputs still remain and very few numerical models have direct utility in urban planning and environmental management (e.g. Cirillo et al. 1997, Pielke \& Uliasz 1998, Eliasson 2000).

An environmental wind tunnel is one example of a physical model that is used to predict flow patterns of planned structures. Circulation within street canyons, including the dispersion of pollutants, and the comfort and safety of pedestrians as well as thermal effects in 
the urban environment have been studied by physical models (Oke 1984, Arnfield 1998a,b, 2001, Plate 1999). The use of physical models in urban planning, despite its great potential, has been uncommon, except for specific projects (e.g. Lindqvist 1991, Hölscher \& Romberg 1996, Plate 1999, Baumueller et al. 2000).

Empirically based methods are defined by Oke (1984) as 'linked by the common feature of reliance upon an empirical data base' and include methods such as statistical algorithms, parameterisations, engineering formulae and qualitative conceptualisations. A recent study reveals that this class of methods is the most frequent, but unsystematically, used of methods for implementing climatic aspects in the Swedish planning process (Eliasson 2000). Empirically based methods have a strength as they are founded on 'real world' data, but the weakness is that these methods often are restricted to a specific location. Several attempts have been made to develop general models based on empirical data (e.g. Laughlin \& Kalma 1990, Bogren et al. 1992, Chaloulakau et al. 1999). Another type of empirical model is the local climate map that has been developed in many countries during the past decades in order to illustrate the spatial variation of climate (e.g. Lindqvist \& Mattsson 1989, Paszynski 1990/91, Lazar \& Podesser 1999, Scherer et al. 1999). Local climatic maps have proved to be a suitable tool for bridging the gap in communication between climatologists and planners (Lindqvist \& Mattsson 1989, Scherer et al. 1999).

Climate knowledge is rarely used in urban planning, because there is a lack of easily accessible tools for implementation (Oke 1984, Lindqvist \& Mattsson 1989, Pressman 1996, Mills 1999, Eliasson 2000). A balanced combination of numerical, physical and empirical models would probably increase the use of climate knowledge, but success is dependent on the availability and accessibility of the methods. Geographical Information System (GIS) as a tool for practical planning has gained much attention during the last decade and is currently used by many city authorities in several countries, including Sweden. With GIS it is possible to manage and visualise geospatial information, and different management strategies could thus be integrated into the urban planning process.

A GIS based empirical technique or model, designed to simulate wind and/or temperature variations in a landscape during different weather conditions and time periods (hours, days and months), has been developed by the authors; the technique is applied on nocturnal data. This paper includes the following parts:

- A description of the technique based on meteorological statistics from one permanent weather station, a digital local climate map and a digital land use map.

- An analysis of data from a network of temperature stations to describe the air temperature variations in the Göteborg urban district during clear and calm nights.

- An evaluation of the GIS technique by a comparison of simulated data and data measured within the temperature network.

- An application of the GIS model on clear, calm weather conditions at night.

- A discussion of further improvements of the GIS model.

\section{STUDY AREA}

The city of Göteborg is situated on the Swedish west coast at latitude $57^{\circ} 42^{\prime} \mathrm{N}$ around the shores of the Göta river (Fig. 1). The study area is the Göteborg urban district (about 72200 ha in size) with a population of approximately 500000 inhabitants. The area is geomorphologically classified as a joint aligned valley landscape dominated by 4 large and broad valleys. The valley bottoms are located less then $10 \mathrm{~m}$ above sea level and they are rather flat and filled with marine

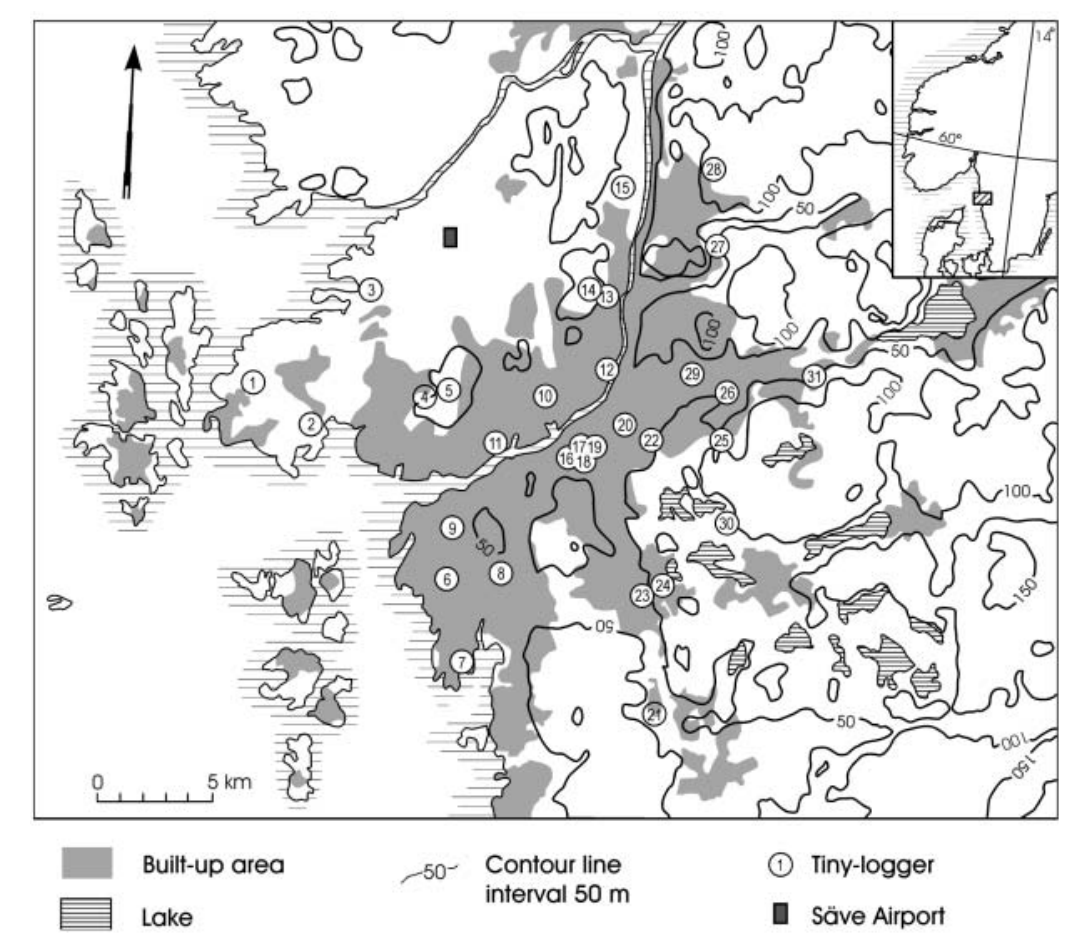

Fig. 1. Location of the 31 fixed Tiny-logger stations in the study area 


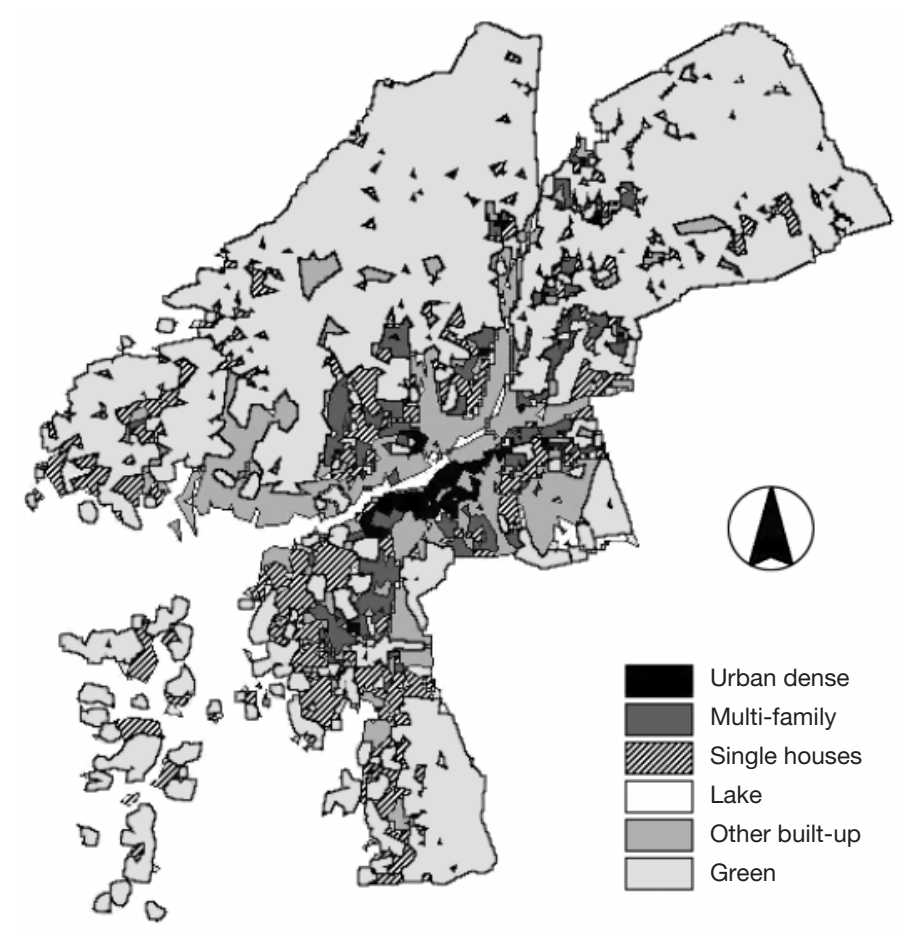

Fig. 2. Map showing the land use in the Göteborg urban district

clay. The coastline is irregular and borders an archipelago with scattered small islands.

Göteborg was founded as a city in 1621 and was built according to Dutch patterns with streets and manmade canals in a strictly designed system. The rather small city centre has a dense building structure with a sky view factor (SVF) in canyons ranging between 0.2 and 0.5 (Eliasson 1992). The sky view factor in suburban areas with detached houses and multi-storey blocks is approximately 0.9. Göteborg is a green city in that it has large areas of forested, agricultural and meadow land. The more densely built up city centre occupies approximately $2 \%$ of the area, multi-family and single houses $9 \%$ and other built up areas another $11 \%$ (Fig. 2). Agricultural and meadow land cover make up $11 \%$, forested areas another $44 \%$ and 'other green areas' (cemeteries, allotments, etc.) $14 \%$.

The climate of the Swedish west coast is dominated by the Westerlies and numerous cyclone passages but blocking high-pressure situations are frequent as well. Göteborg has a typical maritime climate with relatively warm winters and cool summers with mean temperatures of -0.4 and $16.3^{\circ} \mathrm{C}$ respectively.

\section{DESCRIPTION OF THE TECHNIQUE}

The GIS based empirical model is based on mapped information on land use, local climate and climate data from a nearby open meteorological station. The technique uses digital land use, climate information and algorithms to calculate temperature and wind. Processes influencing the local climate are presented in a local climate map. These processes were parameterised and tuned with the aid of calibration measurements (Holmer \& Linderstad 1985). The corrected values were then used to create algorithms. The advantages of using GIS databases are that they may easily be changed and updated. GIS software (PC ARC/INFO, ArcView and IDRISI $^{1}$ ) is used to construct and process the digital maps. The study area is divided into pixels with a $500 \times$ $500 \mathrm{~m}$ resolution, as this is a suitable scale for the comprehensive planning level. Depending on the purpose of the model, the resolution can be changed, e.g. to a $100 \times 100 \mathrm{~m}$ grid depending on the resolution of the input maps. Parts of this method have been presented in a Swedish report by Holmer \& Linderstad (1985) which gives an estimation of the relationship between local climatic variations and energy consumption in an urban area. Since this report is not readily available, a detailed presentation of the method is made in this paper.

\subsection{Input data}

Hourly data on wind speed, wind direction, temperature and cloud cover from one permanent mast at Säve airport weather station (Fig. 1), run by the Swedish Air Force/Military Weather Service, are used as input. The station is situated in an open rural part of the Göteborg urban district and data are measured according to Swedish standards for meteorological observations. Wind measurements are made at $10 \mathrm{~m}$ height and the wind speed is measured with a Vaisala wind anemometer (WAA 15) with accuracy and threshold of \pm 0.1 and $0.5 \mathrm{~m} \mathrm{~s}^{-1}$ respectively. Wind direction is measured with a Vaisala wind vane (WAV15) with accuracy and threshold values of $\pm 3^{\circ}$ and $\pm 0.3 \mathrm{~m} \mathrm{~s}^{-1}$ respectively. Temperature is measured at $2 \mathrm{~m}$ height with a platinum resistant element (PT 100) with an accuracy of $\pm 0.8^{\circ} \mathrm{C}$ at $0^{\circ} \mathrm{C}$ and cloud cover is measured with mobile cloud cover equipment (CBME).

The climate map (scale 1:50 000) illustrates different local climate features in the area. The method used for the development of a climate map, described by Lindqvist \& Mattsson (1989), includes field reconnaissance, studies of maps and air photos, and mobile and

${ }^{1} \mathrm{PC}$ ARC/INFO version 3.4.2. (386), Environmental Systems Research Institute, 380 New York St., Redlands, CA 92373, USA; Arc View 2.1b. Environmental Systems Research Institute, Inc; IDRISI for Windows (1997) Clark Labs, The Idrisi Project, Clark University Graduate School of Geography, 950 Main St. Worcester, MA 01610-1477, USA 


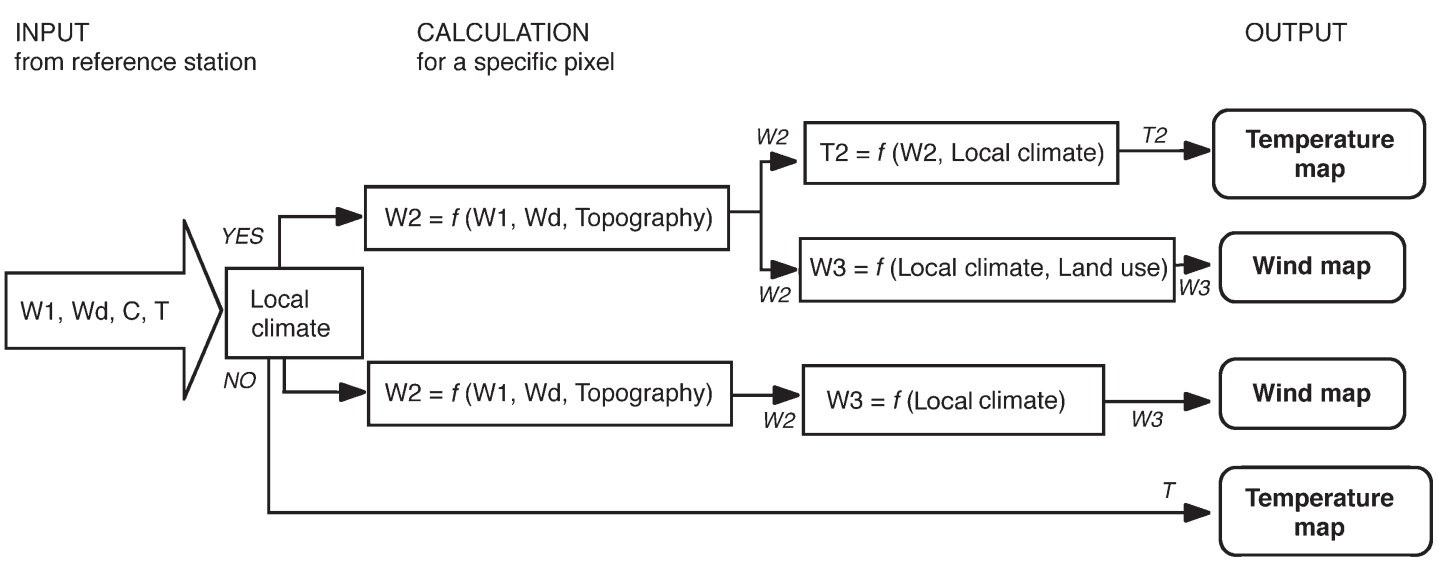

Fig. 3. Conceptual framework. Input data to the model are wind velocity (W1), wind direction (Wd), air temperature (T) and cloud amount $(C)$ from the reference station. For every pixel the wind velocity is corrected for topographic features depending on wind direction and used as an input in a regression equation to give temperature. The calculated temperature value depends on the local climate effect of features such as cold air flows and the urban heat island. Similar corrections are made also for wind calculations with the addition of a correction for land use

permanent measurements of climate elements. The local climate map includes a mixture of process-related features that influence temperature. The features are cold air flows/lakes, strong wind areas (e.g. coastal areas and elevated areas), dampened sea areas (coastal areas affected by a reduced diurnal mean temperature), cool high-level areas and the urban heat island.

The land use map (scale 1:50 000) is the Master Plan used at the Comprehensive Planning Department, Municipality of Göteborg. It consists of 12 different land use classes, which can be divided into 3 categories: man-made areas ( 7 classes), vegetation-covered areas (4) and lakes (1). Fig. 2 shows an aggregated version of the Master Plan (I. Eliasson \& M. Svensson unpubl.).

\subsection{Algorithms}

The modelling technique uses the software MAT$\mathrm{LAB}^{\circledR 2}$ and is designed to simulate temperature and wind variations during different weather situations and different periods (hours, days, months). Meteorological input data are wind speed, wind direction and cloud cover from the reference station. Algorithms are used to calculate temperature and wind due to clouds, topography and the effect of distance from coast. The actual temperature, or wind speed, for every pixel is calculated based on the specific conditions in that pixel. Following the conceptual framework (Fig. 3), the wind speed is, depending on the wind direction, corrected for topography. The corrected wind speed is

${ }^{2}$ MATLAB $^{\circledR}$ (1999) The Language of Technical Computing. Version 5.3.0.10183 (R11), The MathWorks, Inc either used as an input in a regression equation to give the temperature deviation from the reference station or as an input to give the wind speed in a pixel. In the latter case the wind speed is modified according to local climate features and/or land use. The algorithms used in the method are described below. Coefficients referred to are for nighttime only. The output from the model is a temperature deviation from the meteorological reference station (Fig. 1, Säve airport) or alternatively the wind speed (Fig. 3).

\subsubsection{Local wind variations}

Land-use and distance to the sea affect the local wind. The wind speed $U$ at the reference station is

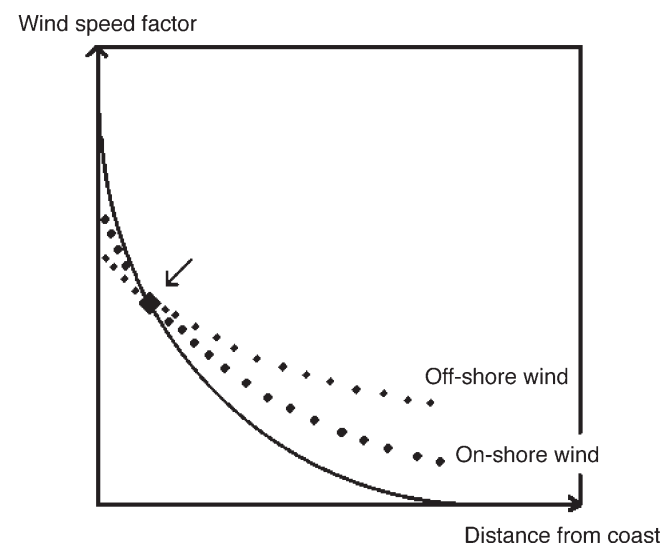

Fig. 4. Variation of the wind speed factor $\exp ^{(c \times d)}$ with distance from the coast. The arrow shows the location of the reference station. The solid black line represents stable nocturnal conditions. Modified after Holmer \& Linderstad (1985) 
Table 1. Factors for calculating the urban open wind divided according to topography and wind direction

\begin{tabular}{|lll|}
\hline Topography & Wind direction & Coefficient, $c$ \\
\hline Valley areas & All wind directions & -0.05 \\
Other areas & WNW, W, WSW, SW & -0.015 \\
& NW, NNW, S, SSW & -0.009 \\
& Other wind directions & -0.007 \\
\hline
\end{tabular}

measured at $10 \mathrm{~m}$ height $\left(U_{10}\right)$. Based on the work of Davenport (1965) a power law function with the exponent of 0.17 is used to recalculate the wind speed at 10 $\mathrm{m}$ to the $5 \mathrm{~m}$ level. The $5 \mathrm{~m}$ level is chosen as it corresponds to roof level (canopy layer) in the area. As a result, the measured wind speed is reduced to $87 \%$ to give the wind speed at the $5 \mathrm{~m}$ level $\left(U_{\text {ref }}\right)$ according to Eq. (1):

$$
U_{\text {ref }}=0.87 \times U_{10}
$$

Calibration measurements have shown that the wind decreases exponentially inland with distance from the sea (Fig. 4). This is true for open areas with similar surroundings. Open area wind $\left(U_{\mathrm{o}}\right)$ is calculated according to Eq. (2) where $c$ is a factor depending on the time of day, topography and wind direction (Table 1) and $d$ is the distance from the sea in kilometres. exp is the base of the natural logarithm.

$$
U_{\mathrm{o}}=U_{\mathrm{ref}} \exp ^{(c \times d)}
$$

The wind speed in open areas $\left(U_{\mathrm{o}}\right)$ is multiplied with a surrounding factor $(S f)$ that depends on the nearest surroundings and the result is modified wind, $U_{\text {mod }}$ calculated according to Eq. (3). This Sf-factor increases wind speed in those areas most influenced by strong wind but it also decreases the wind speed by $90 \%$ in closely built up areas. Both the $c$ and $S f$ coefficients are derived from calibration measurements in the area and $S f$ is determined from land use and climate maps of the area (Table 2).

$$
U_{\text {mod }}=U_{\mathrm{o}} \times S f
$$

\subsubsection{Local temperature deviations}

Table 2. Effect of different environments on the wind velocity is controlled by a surrounding factor $(S f)$. This coefficient is determined from the land use and climate map

\begin{tabular}{|lc}
\hline Surrounding & Sf \\
\hline Mixed urban buildings & 0.1 \\
Scattered multi-storey blocks, detached houses and & \\
gardens, large institutions, offices, industries, etc. & 0.3 \\
Strong wind areas & 1.3 \\
Extreme strong wind areas & 1.6 \\
Other & 0.7 \\
\hline
\end{tabular}

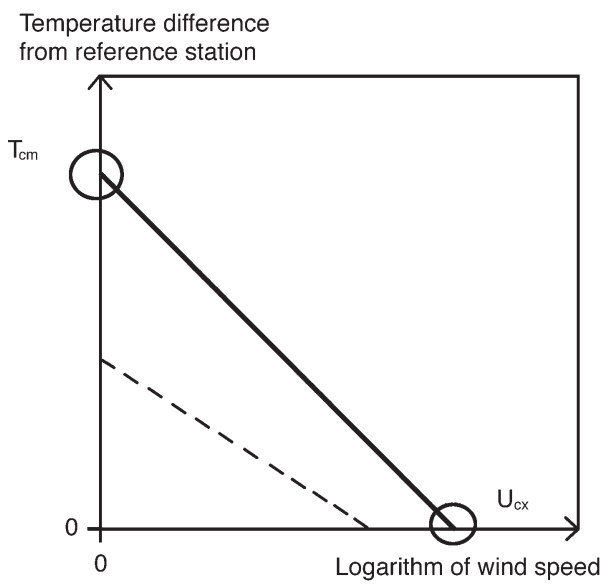

Fig. 5. Linear relationship between the temperature deviation and the logarithmic wind speed determined by the definition of 2 points, the maximum temperature deviation $\left(T_{\mathrm{cm}}\right)$ and the logarithm of wind speed when there is no temperature deviation $\left(U_{\mathrm{cx}}\right)$. The solid black line represents clear conditions and the dashed line the cloudy conditions. Modified after Holmer \& Linderstad (1985)

The model calculates local temperature deviations for pixels with climate features such as cold air flows, lakes, coastal areas, cool high level areas and urban heat island. Empirical studies show a linear relationship between temperature deviation and logarithmic wind speed. The temperature differences are larger during clear weather (Fig. 5). The temperature deviation is calculated for both clear $\left(T_{\mathrm{C}}\right)$ and cloudy $\left(T_{\mathrm{y}}\right)$ conditions depending on wind speed $\left(U_{\mathrm{o}}\right)$. The linear relationship is determined by the definition of 2 points (Fig. 5). The first point is defined as the maximum temperature deviation possible $\left(T_{\mathrm{cm}}\right)$ and is assumed to exist when the wind speed at the reference station is $0 \mathrm{~m} \mathrm{~s}^{-1}$. Even though $0 \mathrm{~m}$ $\mathrm{s}^{-1}$ is recorded, there usually is some wind. The wind speed $\left(U_{\mathrm{cm}}\right)$ at $T_{\mathrm{cm}}$ is therefore set to $0.25 \mathrm{~m} \mathrm{~s}^{-1}$, which is half the threshold value of the anemometer; this assumption is necessary for mathematical reasons. The second point is defined as the wind speed when the temperature deviation is 0 , i.e. $U_{\mathrm{cx}}$. The parameters used in Eqs. (4) \& (5) are given in Table 3.

$$
\begin{aligned}
& T_{\mathrm{c}}=T_{\mathrm{cm}}\left(\log U_{\mathrm{cx}}-\log U_{\mathrm{o}}\right) /\left(\log U_{\mathrm{cx}}-\log U_{\mathrm{cm}}\right) \\
& T_{\mathrm{y}}=T_{\mathrm{ym}}\left(\log U_{\mathrm{yx}}-\log U_{\mathrm{o}}\right) /\left(\log U_{\mathrm{yx}}-\log U_{\mathrm{ym}}\right)
\end{aligned}
$$

where $T$ is temperature, $U$ is wind speed and subscripts are clear (c), cloudy (y), max effect (m), no effect (x) and actual (a).

\subsubsection{Clouds}

The effect of clouds is to dampen the temperature deviations. This is expressed as the cloud factor, $C f$ 
Table 3. Local climate features in the climate map are parameterised after calibration measurements into the following factors. These factors are used to calculate temperature from wind data. Notice that $U_{\mathrm{cm}}$ and $U_{\mathrm{ym}}$ are constant with a value of $0.25 \mathrm{~m} \mathrm{~s}^{-1}$

\begin{tabular}{|lccrc|}
\hline \multirow{2}{*}{ Local climate feature } & \multicolumn{2}{c}{ Clear night } & \multicolumn{2}{c|}{ Cloudy night } \\
& $T_{\mathrm{cm}}\left({ }^{\circ} \mathrm{C}\right)$ & $U_{\mathrm{cx}}\left(\mathrm{m} \mathrm{s}^{-1}\right)$ & $T_{\mathrm{ym}}\left({ }^{\circ} \mathrm{C}\right)$ & $U_{\mathrm{yx}}\left(\mathrm{m} \mathrm{s}^{-1}\right)$ \\
\hline Dampened sea area, extreme & +2 & 15 & +1 & 15 \\
Dampened sea area, moderate & +1 & 10 & +0.5 & 10 \\
Cold air lake, extreme & -6 & 6 & -1 & 3 \\
Cold air lake, strong & -4 & 6 & -1 & 3 \\
Cold air lake, moderate & -2 & 3 & 0 & 0 \\
Heat island, extreme & +5 & 9 & +2 & 6 \\
Heat island, moderate & +2 & 6 & 0 & 0 \\
& & & & \\
\hline
\end{tabular}

nal points and 1 pair in the inner city of Göteborg. In every pair, one of the Tiny-loggers was placed in a relatively low area and the other in the nearest elevated area with similar surroundings. The maximum distance between paired Tiny-loggers was $100 \mathrm{~m}$ and their relative altitude varied between 44 and $75 \mathrm{~m}$.

The sensor of the Tiny-loggers is a $10 \mathrm{k}$ NTC thermistor (encapsulated) with a time-constant $(63 \%)$ in air of $11 \mathrm{~min}$. The sensor accuracy is $\pm 0.2^{\circ} \mathrm{C}$ from 0 to $70^{\circ} \mathrm{C}$ and the resolution of the system is $0.03^{\circ} \mathrm{C}$ at $25^{\circ} \mathrm{C}$. To

(Table 4). Field studies performed in Göteborg show that the dampening effect is small, up to 2 octas, and thereafter the temperature effect is dampened quickly with increasing cloud cover. The differences between 6 and 8 octas are also small.

The actual temperature $\left(T_{\mathrm{a}}\right)$ in the specific pixel during the specific weather situation is then calculated according to Eq. (6).

$$
T_{\mathrm{a}}=T_{\mathrm{c}}-\left(T_{\mathrm{c}}-T_{\mathrm{y}}\right) \times C f
$$

\section{MONITORING NETWORK}

\subsection{Instrumentation}

Hourly temperature data from 31 stationary measurement sites (Fig. 1) were collected and used in the analysis and description of the temperature variations in the area, and for verification of the simulated temperature pattern. Hence, air temperature data sampled at these 31 stations were not used in the development of algorithms. At each station a Tiny-logger (INTAB Interface-Teknik AB), was used to measure temperature once every hour and store the data. The Tiny-logger is covered with a radiation shield and placed $2 \mathrm{~m}$ above the ground. The stations were placed to cover the whole study area and sample the different land uses in the district. The stations were divided into 3 groups according to height, with 21 Tiny-loggers being placed at an altitude between 0 and 30 m, 6 Tiny-loggers $75 \mathrm{~m}$ above sea level and 4 Tiny-loggers between 35 and $60 \mathrm{~m}$. Ten of the Tiny-loggers were also placed out in 5 'high-low pairs', 1 pair at each of the 4 cardi-

Table 4 . The effect of clouds on the temperature expressed as the cloud factor, $C f$

\begin{tabular}{|lccccccccc|}
\hline Cloud cover, C (octas) & 0 & 1 & 2 & 3 & 4 & 5 & 6 & 7 & 8 \\
$C f$ & 0.00 & 0.05 & 0.10 & 0.40 & 0.70 & 0.80 & 0.90 & 0.95 & 1.00 \\
\hline
\end{tabular}

determine if there were any instrument differences between the Tiny-loggers, they were run next to each other in a climate chamber having an accuracy of $0.1^{\circ} \mathrm{C}$. In this case the instruments were tested for temperatures ranging from room temperature (approximately $+20^{\circ} \mathrm{C}$ ) to $-18^{\circ} \mathrm{C}$ and they recorded the temperature every $5 \mathrm{~min}$. The inter-comparison was done before the measurements started and after approximately 1 yr of measurements. The test showed that all Tiny-loggers ran together in a narrow interval with a maximum variation of $0.5^{\circ} \mathrm{C}$. The largest differences, i.e. $0.5^{\circ} \mathrm{C}$, occurred at temperatures below $-10^{\circ} \mathrm{C}$. The Tiny-loggers were also moved randomly between the fixed measurement sites during the measurement period, as data were collected every second month, to smooth out the differences.

\subsection{Selection of network data}

Data (wind speed and cloud information) from the reference station (Säve airport, Fig. 1) were used to identify clear and calm nights. During the period from October 1998 to December 1999, 50 nights were considered to be clear and calm. For a night to be defined as 'clear', the sum of the cloud amount observed during the night must be less than $23 \%$ of the maximum amount possible. This definition follows the selection rules used in meteorological statistics published by the Swedish Meteorological and Hydrological Institute (Taesler 1972). The criterion for a calm night is a wind speed less than or equal to 2 Beaufort $\left(\leq 3.3 \mathrm{~m} \mathrm{~s}^{-1}\right)$. Due to theft and technical problems with some Tinyloggers, the 50 occasions of clear and calm nights were reduced to 34 . Table 5 shows the weather information for 26 of these situations for which the GIS technique was tested. Table 5 also shows the variation within clear and calm conditions. 
Table 5. Weather conditions during the 26 clear and calm occasions used in the study. Air temperature was measured with Tiny-loggers; data on wind speed, wind direction and cloud cover are from the reference station

\begin{tabular}{|c|c|c|c|c|c|c|c|}
\hline \multirow{2}{*}{$\begin{array}{l}\text { Date } \\
\text { (yy/mm/dd) }\end{array}$} & \multicolumn{4}{|c|}{ Air temperature $\left({ }^{\circ} \mathrm{C}\right)$} & \multicolumn{3}{|c|}{ Reference station } \\
\hline & Mean & Min & Max & Range & $\begin{array}{c}\text { Wind } \\
\text { direction }\left({ }^{\circ}\right)\end{array}$ & $\begin{array}{l}\text { Wind speed } \\
\left(\mathrm{m} \mathrm{s}^{-1}\right)\end{array}$ & $\begin{array}{l}\text { Cloud } \\
\text { (octas) }\end{array}$ \\
\hline $99 / 11 / 14$ & -0.42 & -2.89 & 1.76 & 4.65 & 35 & 2.00 & 1 \\
\hline $99 / 05 / 15$ & 2.74 & -0.32 & 6.96 & 7.28 & 14 & 0.52 & 1 \\
\hline $99 / 08 / 28$ & 11.41 & 8.34 & 14.79 & 6.45 & 10 & 0.52 & 1 \\
\hline $98 / 10 / 06$ & 5.69 & 4.76 & 6.73 & 1.97 & 70 & 2.06 & 1 \\
\hline $98 / 10 / 20$ & 0.43 & -1.67 & 4.45 & 6.12 & 140 & 1.03 & 1 \\
\hline $98 / 11 / 30$ & -2.88 & -5.00 & -1.51 & 3.49 & 8 & 0.52 & 0 \\
\hline $99 / 01 / 29$ & -9.09 & -11.45 & -5.18 & 6.27 & 12 & 0.52 & 2 \\
\hline $99 / 03 / 19$ & 0.44 & -1.59 & 3.23 & 4.82 & 16 & 1.55 & 2 \\
\hline $99 / 03 / 22$ & -1.58 & -3.22 & 0.10 & 3.32 & 19 & 0.52 & 0 \\
\hline $99 / 05 / 02$ & 1.83 & -1.59 & 6.20 & 7.79 & 11 & 0.52 & 1 \\
\hline $99 / 05 / 27$ & 9.15 & 5.87 & 12.46 & 6.59 & 14 & 1.03 & 1 \\
\hline $99 / 05 / 30$ & 4.77 & 1.63 & 8.61 & 6.98 & 33 & 0.55 & 2 \\
\hline $99 / 06 / 14$ & 11.43 & 8.09 & 14.36 & 6.27 & 23 & 1.55 & 2 \\
\hline $99 / 06 / 21$ & 9.76 & 6.46 & 12.21 & 5.75 & 12 & 1.55 & 1 \\
\hline $99 / 11 / 10$ & -0.22 & -2.17 & 3.93 & 6.10 & 16 & 1.00 & 1 \\
\hline $99 / 02 / 08$ & -9.66 & -13.99 & $\begin{array}{r}-7.28 \\
-7.28\end{array}$ & 6.71 & 2 & $\begin{array}{l}1.00 \\
1.03\end{array}$ & $\begin{array}{l}1 \\
2\end{array}$ \\
\hline $99 / 05 / 19$ & 8.85 & 5.62 & 12.63 & 7.01 & 12 & 0.52 & 0 \\
\hline $99 / 09 / 06$ & 14.50 & 10.11 & 17.95 & 7.84 & 0 & 0 & 1 \\
\hline $99 / 08 / 24$ & 9.65 & 6.78 & 13.73 & 6.95 & 0 & 0 & 0 \\
\hline $99 / 05 / 18$ & 5.90 & 2.72 & 10.18 & 7.46 & 0 & 0 & 2 \\
\hline $99 / 05 / 07$ & 4.50 & -0.07 & 8.06 & 8.13 & 0 & 0 & 0 \\
\hline $99 / 05 / 06$ & 3.25 & -0.23 & 7.74 & 7.97 & 0 & 0 & 0 \\
\hline $99 / 05 / 03$ & 2.80 & -0.58 & 6.92 & 7.50 & 0 & 0 & 0 \\
\hline $99 / 04 / 27$ & 6.42 & 2.99 & 11.00 & 8.01 & 0 & 0 & 1 \\
\hline $99 / 04 / 02$ & 5.50 & 2.16 & 9.19 & 7.03 & 35 & 0 & 1 \\
\hline $98 / 11 / 02$ & -0.97 & -1.82 & 0.12 & 1.94 & 280 & 0 & 1 \\
\hline
\end{tabular}

\subsection{Temperature variations in the area}

Temperature recordings at the 31 permanent stations (Fig. 1) showed a considerable temperature variation in the study area during clear and calm nights. Hourly temperature data from sunset and $6 \mathrm{~h}$ later were analysed on a monthly and seasonal basis. Spring is hereafter defined as the months March to May, summer as June to August, autumn as September to November and winter as December to February. The temperature pattern is complex due to differences in altitude and land use, but also due to effects of the sea. However, we chose representative points/profiles in order to estimate the effects of each factor.

The maximum temperature difference resulting from urban heat island, distance from the sea and altitude during individual nights was analysed (Table 6). The heat island effect is shown in Fig. 6. A profile in the northto-south direction composed of stations situated approximately at the same distance from the coast $(\sim 14 \mathrm{~km})$ and at the same relative altitude (5 to $20 \mathrm{~m}$ ) was chosen to standardise the influence of the sea (Fig. 6). Fig. 6a,b are based on 30 occasions. Fig. 6a presents a seasonal basis with mean temperature values at the stations in the profile. The overall pattern in the profile is the same regardless of season, but the temperature interval is different. The yearly mean heat island intensity during clear and calm nights increases from $2.6^{\circ} \mathrm{C}$ at sunset to $4.2^{\circ} \mathrm{C}$ $3 \mathrm{~h}$ after sunset (Fig. 6b). The maximum urban-rural temperature difference for north and south directions is illustrated in Table 6. The north station (13) and the south station (8) are located approximately 10 and $15 \mathrm{~km}$ respectively from the city centre station (17). The maximum urban-rural temperature difference ranged from 5 to $8.5^{\circ} \mathrm{C}$ depending on season and station location.

The temperature difference between Stn 1, near the coast, and the inland station 29 (18 km distance difference, Fig. 1) shows that the coast station is from $4.2^{\circ} \mathrm{C}$ up to $8.1^{\circ} \mathrm{C}$ warmer than the inland station depending on season (Table 6). Fig. 7 further illustrates this effect; the heat island effect, discussed above, is also visible. Fig. $7 \mathrm{a}, \mathrm{b}$ are based on the same data -30 clear and calm nights. In Fig. $7 \mathrm{a}$ the data are presented as mean values at stations in a profile from the coast (Stn 1) and inland during different seasons (station location is shown in Fig. 1). The pattern is the same during the 4

Table 6. Maximum air temperature differences $\left(\Delta T^{\circ} \mathrm{C}\right)$ during individual nights. $\mathrm{n}=$ number of clear, calm nights

\begin{tabular}{|c|c|c|c|c|c|}
\hline \multirow[t]{2}{*}{$\Delta T^{\circ} \mathrm{C}$} & \multirow{2}{*}{$\begin{array}{l}\text { Distance to coast } \\
\text { Stns } 1 \text { and } 29\end{array}$} & \multicolumn{2}{|c|}{ Urban heat island } & \multicolumn{2}{|c|}{ Altitude, high-low pairs } \\
\hline & & North (Stns 17 and 13) & South (Stns 17 and 8) & Stns 24 and 23 & Stns 25 and 26 \\
\hline Spring & $6.9(\mathrm{n}=14)$ & $6.7(\mathrm{n}=14)$ & $8.5(n=14)$ & $4.9(\mathrm{n}=14)$ & $3.9(\mathrm{n}=14)$ \\
\hline Summer & $4.7(\mathrm{n}=5)$ & $5.0(n=5)$ & $5.0(n=5)$ & $1.7(n=5)$ & $1.6(\mathrm{n}=5)$ \\
\hline Autumn & $8.1(n=8)$ & $6.1(n=8)$ & $6.1(n=8)$ & $4.9(\mathrm{n}=11)$ & $4.4(\mathrm{n}=11)$ \\
\hline Winter & $4.2(\mathrm{n}=3)$ & $5.3(n=3)$ & $5.3(n=3)$ & $2.5(\mathrm{n}=1)$ & $2.2(\mathrm{n}=1)$ \\
\hline
\end{tabular}



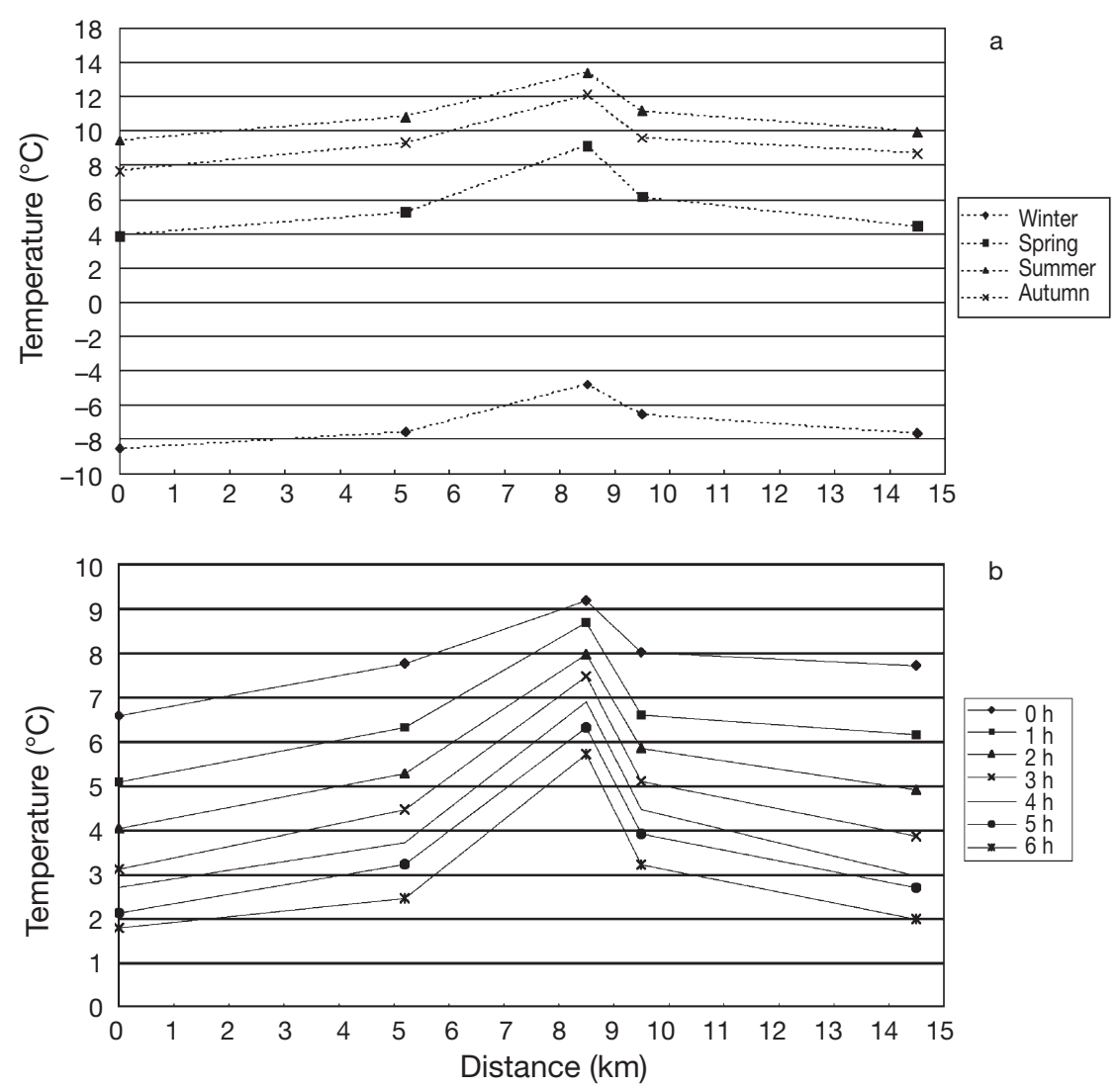

Fig. 6. Air temperature variations in the area based on 30 clear and calm occasions illustrated with a profile from north to south composed of Stns 13, $12,17,16$ and 8 . The stations are located at a relative altitude of $15,5,20$, 15 and 15 m respectively: (a) mean temperature shown on a seasonal basis, at $3 \mathrm{~h}$ after sunset: i.e. 20:00 h winter and autumn: 23:00; spring; and 01:00 $\mathrm{h}$, summer; (b) temperature development during the first $6 \mathrm{~h}$ after sunset on a yearly basis

seasons even though the temperature interval varies. Fig. $7 \mathrm{~b}$ illustrates the yearly mean temperature at these stations and the temperature development during the first $6 \mathrm{~h}$ after sunset. The temperature decrease $6 \mathrm{~h}$ after sunset is $2.2^{\circ} \mathrm{C}$ at a distance of $11 \mathrm{~km}$, i.e. from Stn 1 (located $1 \mathrm{~km}$ from the coast) to Stn $10(12 \mathrm{~km}$ from the coast). The temperature difference between a coastal position and an inland area (Stn 1 and 29) reaches a maximum of $3^{\circ} \mathrm{C} 5 \mathrm{~h}$ after sunset.

The relative altitude in itself produces temperature differences and the sea affects these differences. The minimum and maximum differences vary with season and are somewhat lower than for the other features, but the pattern during different months is the same. The 2 high-low pairs, Stns 24-23 and 25-26 (Table 6), were chosen because they are located at the same distance (i.e. $19 \mathrm{~km}$ ) from the coast and the relative height difference between the 2 stations in each pair is the same (i.e. $75 \mathrm{~m}$ ). Maximum temperature differences ranging from 1.6 to $4.9^{\circ} \mathrm{C}$ are recorded at these high-low station pairs. In station pair 24-23, the high station (24) is always warmer $3 \mathrm{~h}$ after sunset independent of season. The temperature difference between the high-low pair during the first $6 \mathrm{~h}$ after sunset was also analysed on a yearly basis. Air temperature changes by $1.6^{\circ} \mathrm{C}$ during the first $6 \mathrm{~h}$ at night. A shift in temperature occurs $1 \mathrm{~h}$ after sunset when the high station (Stn 24) becomes warmer than the lower station (Stn 23). The high-low station pair 25-26 shows the same temperature development during the first 6 night hours but the change occurs $4 \mathrm{~h}$ after sunset. Due to this later shift, the lower station (26) is always warmer than the higher station (25) $3 \mathrm{~h}$ after sunset. The mean temperature difference at $75 \mathrm{~m}$ relative altitude difference is $3.3^{\circ} \mathrm{C}$.

\section{VERIFICATION OF THE TECHNIQUE}

The results from the monitoring network showed that the development of the nocturnal temperature pattern was similar on all nights. The maximum temperature differences occurred about $3 \mathrm{~h}$ after sunset. Thus the test simulation of the technique and the verification were performed on data collected at this time.

The verification of the technique was performed with data collected in the Tiny-logger monitoring network. The technique was applied using data from the reference station (input) during 26 of the 34 clear and calm nights resulting in 26 different simulations. Cloud observations are necessary to run the model and the reduction from 34 to 26 nights was due to technical problems with the cloud observation technique at the reference station. During occasions when the recorded wind speed at the reference station was $0 \mathrm{~m} \mathrm{~s}^{-1}$, a wind speed of $0.4 \mathrm{~m} \mathrm{~s}^{-1}$ was chosen, as this is slightly lower than the anemometer's threshold value $\left(0.5 \mathrm{~m} \mathrm{~s}^{-1}\right)$.

Results from simulations made with data from the reference station and Tiny-logger measurements in the Göteborg district during the same occasions were compared (Fig. 8). Air temperature simulations were made for all pixels having a Tiny-logger station (25 locations). Observations from the monitoring network were plotted against simulated temperatures. The mean of the 26 clear and calm nights is shown in Fig. 8 at $3 \mathrm{~h}$ after sunset. The black solid line in Fig. 8 indicates the 

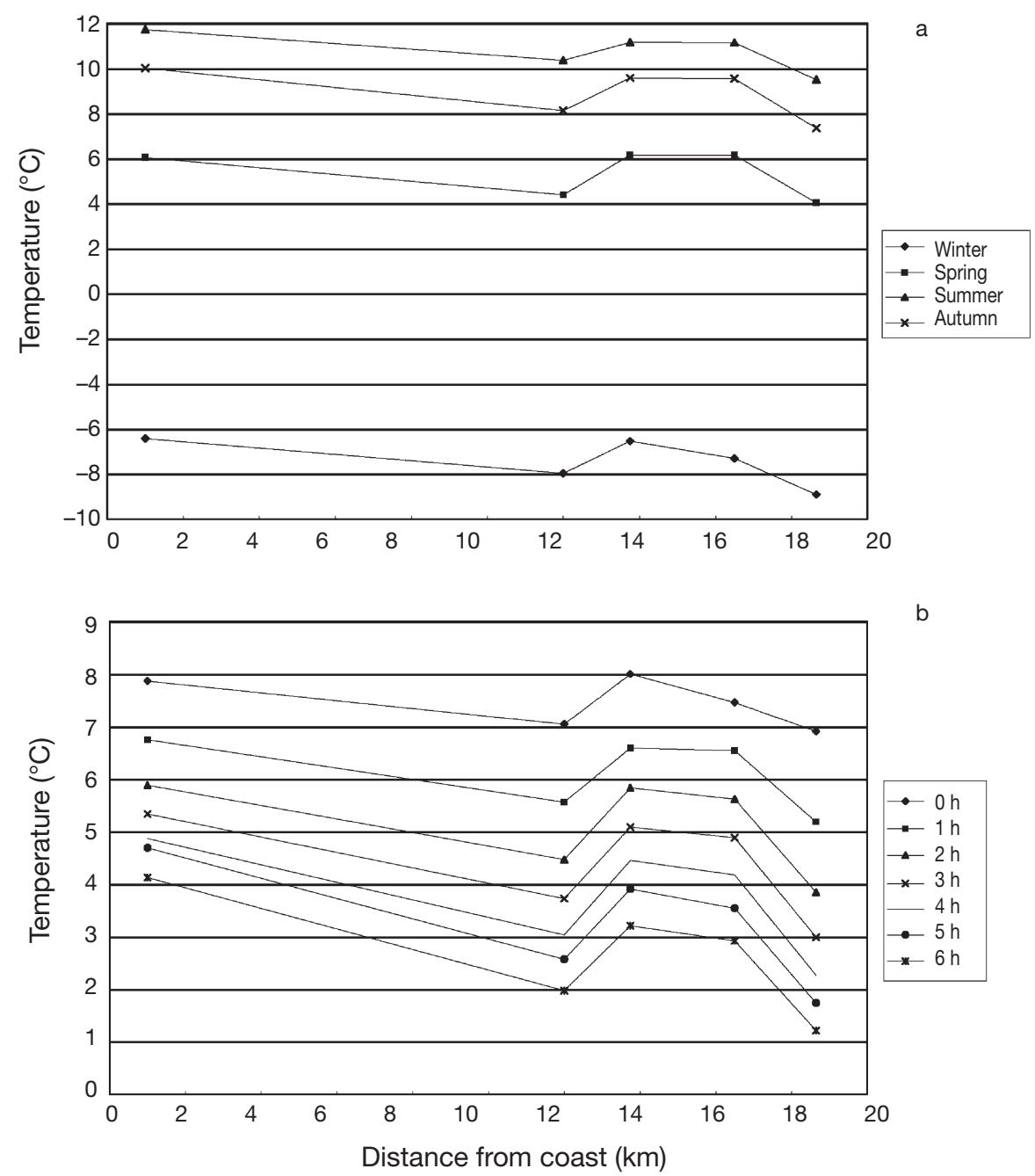

Fig. 7. Temperature variations in the area with data from 30 clear and calm nights in a profile from west to east composed of Stns 1, 10, 16, 20, and 29. Stn 1 is near the coast and Stn 29 has an inland position. From left to right the stations are located at a height of $35,20,15,20$ and $10 \mathrm{~m}$ respectively. (a) Mean temperature at each station according to season at $3 \mathrm{~h}$ after sunset: i.e. 20:00 $\mathrm{h}$ in winter and autumn, 23:00 $\mathrm{h}$ in spring and 01:00 $\mathrm{h}$ in summer. (b) data presented as yearly mean illustrating the temperature development from sunset to $6 \mathrm{~h}$ after sunset for each station in the profile

one-to-one relationship (i.e. ideal) between the calculated and observed data. The dashed black lines show the $\pm 1^{\circ} \mathrm{C}$ difference between calculated and observed temperatures. Twelve stations fall into an interval of $\pm 1^{\circ} \mathrm{C}$ from the best fit between simulations and observations. For 10 stations the model always gives lower temperatures than those recorded, and for 3 stations, it calculates higher temperatures. The coefficient of determination is 0.41 .

The grid size $(500 \times 500 \mathrm{~m})$ may be one reason for the poor match between the observed and calculated data. Large differences in local climate occur over short distances and therefore the pixel size may lead to diffi- culties in the verification as the model calculates a temperature value for each grid while the Tiny-logger measurements are point observations.

\section{APPLICATION OF THE GIS MODEL ON TWO CLEAR CALM NIGHTS}

The model was further tested and simulations were made for one spring and one autumn night with data from the reference station (Figs. 9 \& 10). Spring and autumn were chosen because these seasons showed a high frequency of clear, calm nights. The temperature deviation from the reference station is shown in Figs. $9 \& 10$. Fig. 9 shows a simulation of a midMarch occasion $3 \mathrm{~h}$ after sunset, i.e. at 23:00 $\mathrm{h}$. The wind speed and wind direction at the reference station were $1.5 \mathrm{~m} \mathrm{~s}^{-1}$ and $16^{\circ} \mathrm{N}$ respectively. The cloud cover was 2 octas and the temperature at the reference station was $0.1^{\circ} \mathrm{C}$. The simulation shows a clear pattern with colder areas in the north-south valley and in the elevated areas in the northeastern part of the district. The temperature in the valley is between 2.5 and $3.5^{\circ} \mathrm{C}$ lower than at the reference station and the elevated parts are 1 to $3.5^{\circ} \mathrm{C}$ colder than at the reference station. The heat island effect is also pronounced with 3 to $3.5^{\circ} \mathrm{C}$ higher temperatures in the inner parts of the city. The suburban areas are $1.5^{\circ} \mathrm{C}$ warmer compared with the reference station. The sea effect is also obvious as an approximately $1 \mathrm{~km}$ wide area near the coast is 1 to $2^{\circ} \mathrm{C}$ warmer than the reference station.

The autumn situation (Fig. 10) illustrated by a November night at 20:00 h (3 h after sunset) shows a similar pattern but the differences are larger. The wind speed at the reference station was $1 \mathrm{~m} \mathrm{~s}^{-1}$ and the wind direction $16^{\circ} \mathrm{N}$. The temperature was $-2.2^{\circ} \mathrm{C}$ and a cloud cover of 1 octas was recorded. The north-south valley is 2.5 to $4^{\circ} \mathrm{C}$ colder than the reference station and temperature differences of over $4^{\circ} \mathrm{C}$ exist in the northeastern elevated parts of the district. The coastal zone is, as for the spring occasion, slightly warmer: 1 to $2^{\circ} \mathrm{C}$. The suburban areas are 1.5 to $2^{\circ} \mathrm{C}$ warmer than the reference station and the inner city is 3 to $3.5^{\circ} \mathrm{C}$ warmer. 


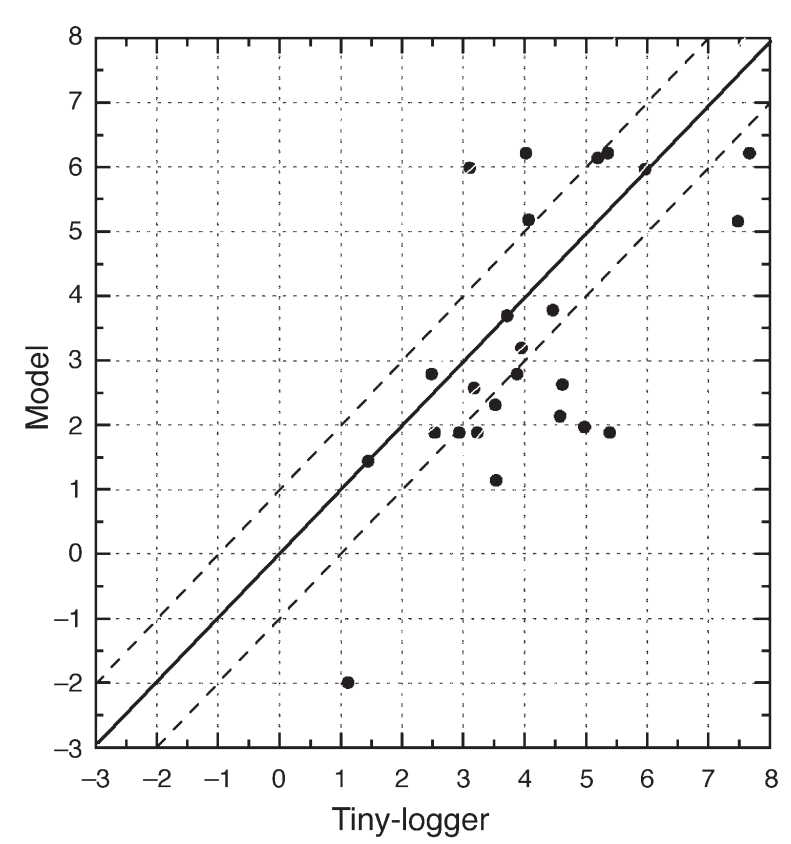

Fig. 8. Regression analysis between simulated (model) and observed (Tiny-logger) air temperatures. The data (solid black dots) are mean values from 25 stations based on 26 clear and calm nights. The solid black line indicates a 1:1 relation between simulations and measurements. Dashed lines show the $\pm 1^{\circ} \mathrm{C}$ deviation from the ideal relationship. The coefficient of determination, $\mathrm{R}^{2}$, is 0.41

In summary, both simulations give similar results. However autumn is more 'extreme' with 1 octas of cloud and $1 \mathrm{~m} \mathrm{~s}^{-1}$ wind speed. As a result there are larger thermal differences in the autumn simulation.

A separate analysis of the difference between observed and calculated temperatures, at $3 \mathrm{~h}$ after sunset, for every station during these 2 occasions (March 19, 1999 [spring] and November 10, 1999 [autumn]) was performed. The results show that for the spring simulation, $60 \%$ of the differences fall in the range of $\pm 1{ }^{\circ} \mathrm{C}$, and $84 \%$ fall in the range of $\pm 1.5^{\circ} \mathrm{C}$. For the autumn simulation $48 \%$ of the differences fall in the range of $\pm 1^{\circ} \mathrm{C}$; while using $\pm 1.5^{\circ} \mathrm{C}$ as the limit, $57 \%$ of the deviations fall in this range. During the autumn night, data from 3 stations $(2,3$ and 15) were missing. The temperature simulations at these stations are good during the measurement period as a whole (mean of the other 24 occasions) and this may be the reason that the results from the verification are somewhat poorer compared with that of spring. The same 13 stations figured in the above two simulation runs and during the comparison of all 26 clear and calm nights.

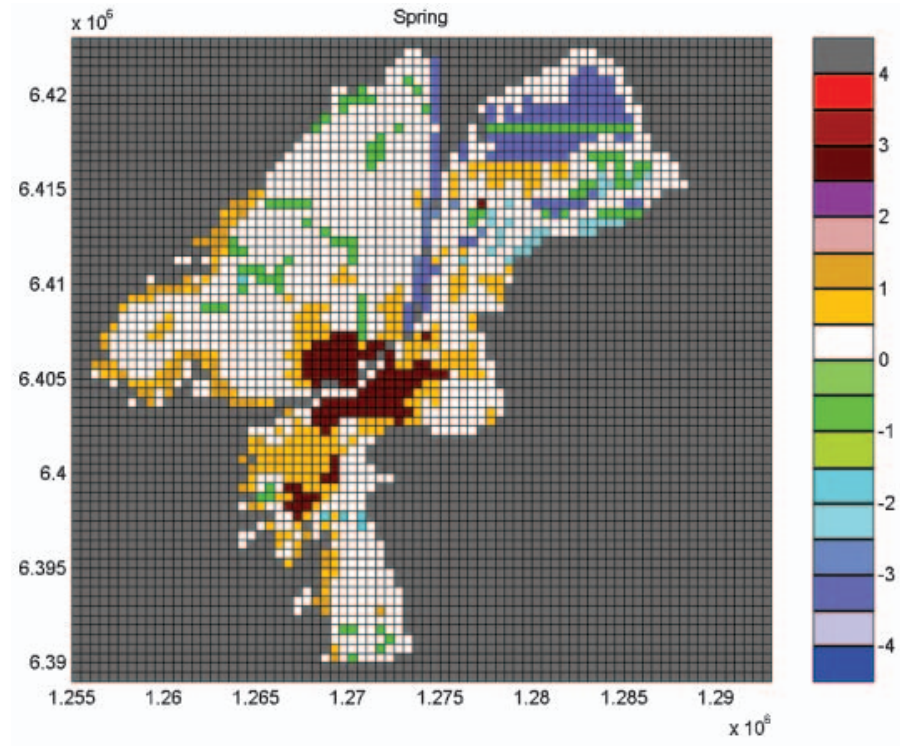

Fig. 9. Simulation of the temperature pattern in late March, $3 \mathrm{~h}$ after sunset. Temperatures given are the deviation from the reference station. At the reference station, the wind speed was $1.5 \mathrm{~m}$ $\mathrm{s}^{-1}$ and the wind direction $16^{\circ} \mathrm{N}$; the temperature was $0.1^{\circ} \mathrm{C}$ and the cloud amount was 2 octas
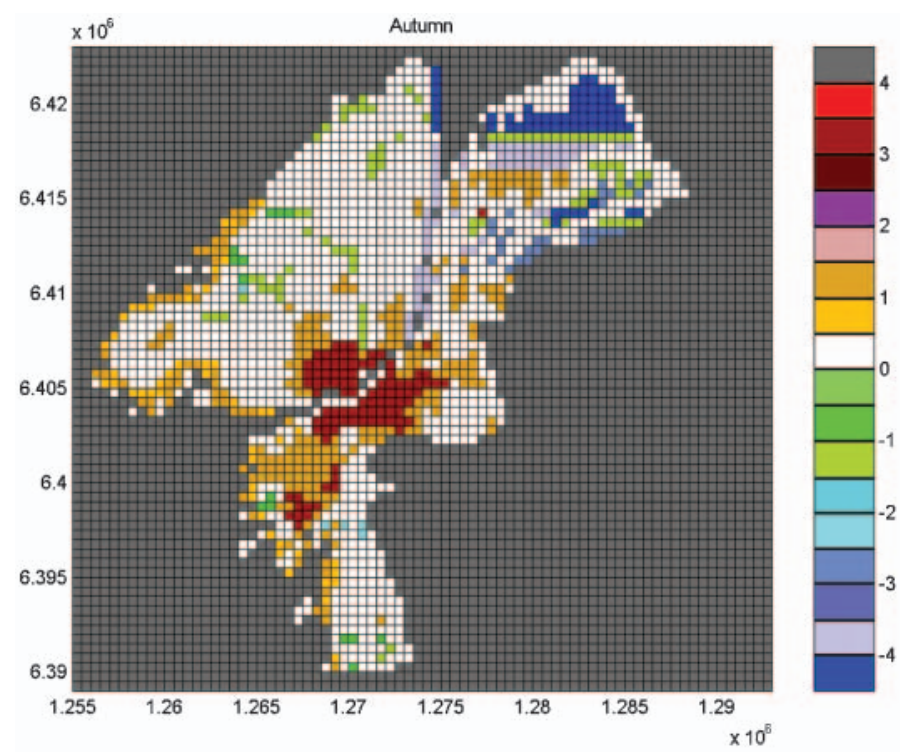

Fig. 10. Simulation of the air temperature pattern in November, 3 $\mathrm{h}$ after sunset. Temperatures given are the deviation from the reference station. The weather conditions at the reference station were: wind speed $1 \mathrm{~m} \mathrm{~s}^{-1}$, wind direction $16^{\circ} \mathrm{N}, 1$ octas cloud cover and air temperature of $-2.2^{\circ} \mathrm{C}$

\section{DISCUSSION AND FURTHER IMPROVEMENTS OF THE TECHNIQUE}

The main advantage with the technique is that it is a local scale model with a resolution suitable for use at the comprehensive planning level. The necessary equipment and data needed to use the method are: a $\mathrm{PC}$, land use information, generalised data for climate 
of the area (local climate map) and data from one meteorological station. As GIS has become a frequent tool in urban planning, its application increases the accessibility of the technique. With GIS it is also possible to incorporate revised maps and new information. The use of an urban planning land use database, the Master Plan, also increases the usefulness of the technique. However, the results presented show that the technique needs some improvements. The main difficulties identified are related to the accuracy of the climate map, grid size and algorithms used.

The accuracy of the climate map is a likely reason for the observed differences between simulations and measurements. The results show that some pixels always received higher or lower temperatures compared to measurements, an effect that could be related to the indicated local climate in those pixels. This is partly an effect of a generalisation of boundaries when the local climate map was created and partly the result of the conversion from a vector-based map to a rougher grid-based map. Another factor causing problems with the verification is related to the grid size. Temperature estimations for a $500 \times 500 \mathrm{~m}$ pixel are compared with point observations during the verification. Thus the location of temperature stations is very important and those located at the boundaries between different climatic features complicate the verification. When analysing stations having higher temperatures, it is clear that the distance from the inner city is of importance. Identification of important urban heat island features in the climate map is mainly based on the structure and sky view factor in urban canyons. An area in the suburbs with the same building structure and design as in the city centre area is given the same weighting as those in the city centre. This could be changed by incorporating an algorithm showing that the urban heat island magnitude is influenced by distance from the city centre (maximum urban heat island) resulting in a reduced urban heat island effect in suburban areas even though the building structure is the same as in the central parts. Alcoforado (1994) shows that distance from city centre is an important factor for determining temperature patterns in Lisbon. On the other hand a statistical analysis presented by I. Eliasson $\&$ M. Svensson (unpubl.) shows that distance from city centre has a small effect on the temperature pattern in Göteborg; so this is a factor that needs to be studied more carefully. The present results also show that some grid cells with model temperatures lower than observed were wrongly classified as situated within cold air pools or flows. In summary these results show that the climate map needs to be checked, modified and improved.

The algorithms and threshold values are assigned a minimum value so as not to overestimate local climate effects. When the reference station records $0 \mathrm{~m} \mathrm{~s}^{-1} \mathrm{a}$ wind speed slightly lower $\left(0.4 \mathrm{~m} \mathrm{~s}^{-1}\right)$ than the threshold value $\left(0.5 \mathrm{~m} \mathrm{~s}^{-1}\right)$ of the anemometer is used in the simulations. Using half the threshold value $\left(0.25 \mathrm{~m} \mathrm{~s}^{-1}\right)$ results in larger climatic effects, and in reality, $0.4 \mathrm{~m} \mathrm{~s}^{-1}$ probably is too high; i.e. the modelled effect is smaller than it is in reality. The reason for this choice is not to overestimate the effects of climate in the method. The power law function used to recalculate the wind from 10 to $5 \mathrm{~m}$ is derived from Davenport (1965). The exponent of 0.17 is designed to represent the smooth undulating landscape around the reference station. A higher coefficient, responding to a slightly rougher surface, would slow down the wind more, enhancing the local climatic effects further.

An examination of the monitoring network showed that the maximum urban-rural temperature difference ranged from 5 to $8.5^{\circ} \mathrm{C}$ depending on season and station. The maximum difference agrees very well with that in other cities with the same population size. Oke (1981) compares city size and maximum urban-rural temperature differences. A value of $7^{\circ} \mathrm{C}$ is common for a city with the population of Göteborg. The algorithms used (Table 3), e.g. $5^{\circ} \mathrm{C}$ increase for an 'extreme heat island area', correspond to the differences observed in the area both with the monitoring network and in studies by Eliasson (1994).

The sea has a significant influence on the temperature pattern in a transition zone between the sea and land, which gives temperature variations during day and night as discussed by Munn (1966) and Oke (1993). Usually water has a warming effect that diminishes at night and our results show that this effect reached a maximum difference of $3^{\circ} \mathrm{C}, 5 \mathrm{~h}$ after sunset. The climate map shows this process as the feature dampened sea areas and the parameterisation values are comparable to our Tiny-logger observations.

The effect of clouds on temperature depends on cloud type (Oke 1993). The net result of clouds is to dampen the diurnal temperature range. The effect on air temperature is larger for low and rather warm stratus clouds. The algorithms dealing with cloud amount are based on calibration measurements for clear and cloudy situations, but the boundary line between clear and cloudy is rather tentative. The technique also uses the total cloud amount; information about cloud type and cloud height is probably better, but difficult to obtain.

Results from the monitoring network showed that the maximum temperature differences during individual nights occur during spring and autumn. The model also gave larger temperature differences in spring and autumn. In a comparison between observations and simulations the autumn simulation produces slightly higher temperature values compared to those observed. The autumn situation is extremely clear and calm (1 octas and $\left.1 \mathrm{~m} \mathrm{~s}^{-1}\right)$ and this results in larger differences. The model probably overestimates the effect 
of clear, calm conditions (Table 3) and the algorithms need some adjusting.

In this paper, a GIS model has been evaluated for clear, calm conditions only. With improvements, the model has the potential for working well in the Göteborg area. Further work required includes a test of the technique for all weather situations and at other sites. It is also clear that the climate map needs improvement. Modifications of the model will be based on the outcome of a statistical analysis of data from the monitoring network (I. Eliasson \& M. Svensson unpubl.) and a comparison with results from other studies. The technique has been tested on data valid for the Göteborg urban district. This can be extended to include input data (land use and climate information) from other areas. The algorithms, however, must be tested and calibrated for the new areas.

Acknowledgements. This study was made possible by the financial support from the Swedish Environmental Protection Agency and the Swedish Society for Anthropology and Geography. We would like to thank lecturer Jan Södersten at the School of Mathematics and Computing, Chalmers University of Technology, for valuable help in programming. We are grateful to Mrs. Solveig Svensson and Mrs. Agneta Malm for drawing one of the maps. We are also grateful for the advice and valuable comments provided by four anonymous referees and the editor.

\section{LITERATURE CITED}

Alcoforado MJ (1994) L'extrapolation spatiale des donnes thermiques en milieu urbain. Publications de l'Association Internationale de Climatologie 7:493-502

Arnfield AJ (1998a) Micro- and mesoclimatology. Prog Phys Geogr 221:103-113

Arnfield AJ (1998b) Micro- and mesoclimatology. Prog Phys Geogr 224:533-544

Arnfield AJ (2000) Micro- and mesoclimatology. Prog Phys Geogr 242:261-271

Arnfield AJ (2001) Micro- and mesoclimatology. Prog Phys Geogr 251:123-133

Baumueller J, Hoffman U, Reuter U (2000) The project ‘Urban Climate 21 - Stuttgart -' Basic materials for urban planning 'Stuttgart 21'. In: de Dear RJ, Kalma JD, Oke TR, Auliciems A (eds) Biometeorology and urban climatology at the turn of the millennium: selected papers from the conference ICBICUC'99, Sydney, WCASP-50, WMO/TD No. 1026:551-555

Bogren J, Gustavsson T, Lindqvist S (1992) A description of a local climatological model used to predict temperature variations along stretches of road. Meteorolog Mag 121:157-164

Chaloulakau A, Assimacopoulos D, Lekkas T (1999) Ozone concentrations in the Athens. Environ Monitor Assm 56:97-112

Cirillo MC, Tamponi M, Zanini G (1997) Italian debate on the role of regulatory models in the framework of the new European directives on air quality. Int J Environ Pollut 8:817-824

Davenport AG (1965) The relationship of wind structure to wind loading. Proc Conf Wind Effects on Struct Sympos 16, Vol 1, HMSO, London, p 53-102

Eliasson I (1992) Infrared thermography and urban temperature patterns. Int J Remote Sensing 13(5):869-879

Eliasson I (1994) Urban-suburban-rural air temperature differences related to street geometry. Phys Geogr 15(1):1-22

Eliasson I (2000) The use of climate knowledge in urban plan- ning. Landsc Urban Plann 48:31-44

Friedrich M, Grätz A, Jendritzky G (2001) Further development of the urban bioclimate model UBIKLIM taking local wind systems into account. Meteorol Z 10(4):267-272

Holmer B, Linderstad H (1985) Energy Index-The local climates effect on the energy consumption. Byggforskningsrådet R115:110 (in Swedish)

Hölscher N, Romberg E (1996) Assessment of road tunnelrelated air pollution by means of wind tunnel simulations. Int Conf Urban Climatol, June 10-14, Essen, Germany

Jendritzky G, Grätz A, Friedrich M (2000) The assessment of human thermal climates in cities. In: de Dear RJ, Kalma JD, Oke TR, Auliciems A (eds) Biometeorology and urban climatology at the turn of the millennium: selected papers from the conference ICB-ICUC'99, Sydney, WCASP-50, WMO/TD No. 1026:65-69

Laughlin GP, Kalma JD (1990) Frost risk mapping for landscape planning: a methodology. Theoret Appl Climatol 42: $41-51$

Lazar R, Podesser A (1999) An urban climate analysis of Graz and its significance for urban planning in the tributary valleys east of Graz (Austria). Atmos Environ 33: 4195-4209

Lindqvist S (1991) Local climatological maps for planning. University of Göteborg, Department of Physical Geography, GUNI report 32

Lindqvist S, Mattsson JO (1989) Topoclimatic maps for different planning levels: some Swedish examples. Build Res Practice, J CIB 5:299-305

Mills G (2000) Urban climatology and urban design. In: de Dear RJ, Kalma JD, Oke TR, Auliciems A (eds) Biometeorology and urban climatology at the turn of the millennium: selected papers from the conference ICB-ICUC'99, Sydney, WCASP-50, WMO/TD No. 1026:541-544

Munn RE (1966) Descriptive micrometeorology. Academic Press, New York

Oke T (1981) Canyon geometry and the nocturnal urban heat island: comparison of scale model and field observations. J Clim 1:237-254

Oke T (1984) Towards a prescription for the greater use of climatic principles in settlement planning. Energy Build 7: $1-10$

Oke TR (1993) Boundary layer climates. Cambridge University Press, Cambridge

Paszynski J (1990/91) Mapping urban topoclimates. Energy Build 15-16:1059-1062

Pielke RA, Pearce RP (1994) Mesoscale modelling of the atmosphere. Amer Meteorol Soc 25:168

Pielke RA, Uliasz M (1998) Use of meteorological models as input to regional and mesoscale air Quality models - limitations and strengths. Atmos Environ 32:1455-1466

Plate E (1999) Methods of investigating urban wind fieldsphysical models. Atmos Environ 33:3981-3989

Pressman NEP (1996) Sustainable winter cities: future directions for planning, policy and design. Atmos Environ 30: 521-529

Scherer D, Fehrenbach HD, Parlow E (1999) Improved concepts and methods in analysis and evaluation of the urban climate for optimizing urban planning processes. Atmos Environ 33:4185-4193

Sturman AP (1998) Applied climatology. Prog Phys Geogr 224:558-565

Sturman AP (2000) Applied climatology. Prog Phys Geogr 241:129-139

Taesler R (1972) Klimatdata för Sverige. KL Beckmans Tryckerier AB, Stockholm

Submitted: November 28, 2000; Accepted: September 20, 2001 Proofs received from author(s): September 6, 2002 